\title{
In-Vitro Investigation of Ceftibuten with Antacid and Metal Interaction, Complexation and Exploration of Antimicrobial Activity
}

\author{
Joushan Ara, ATM Yusuf*, and Md Shahidul Islam \\ Department of pharmacy, University of Science and Technology Chittagong (USTC), Chattogram, Bangladesh
}

*Corresponding author: ATM Yusuf, Department of pharmacy, University of Science and Technology Chittagong (USTC), Chattogram, Bangladesh, E-mail: yusuf07ctg@gmail.com

Received: 18 Mar, 2020 | Accepted: 02 Apr, 2020 | Published: 20 Apr, 2020

Citation: Ara J, Yusuf ATM, Islam S Md (2020) In-Vitro Investigation of Ceftibuten with Antacid and Metal Interaction, Complexation and Exploration of Antimicrobial Activity. J Drug Res Dev 6(1): dx.doi.org/10.16966/2470-1009.151

Copyright: (C) 2020 Ara J, et al. This is an open-access article distributed under the terms of the Creative Commons Attribution License, which permits unrestricted use, distribution, and reproduction in any medium, provided the original author and source are credited.

\begin{abstract}
Recently Ceftibuten is mainly cast-off to treat severe bacterial infections of chronic bronchitis, serious bacterial otitis, pharyngitis, as well as tonsilitis. This is also designated for pneumonia, UTI, enteritis, as well as gastroenteritis. The chief purpose of the current research work was to investigation the in vitro connections of Ceftibuten with important metal salt as well as antacid to govern the bioavailability in view of antimicrobial action of Ceftibuten subsequently drug metal connections at $\mathrm{pH}$ 7.4. Ceftibutenis an antibiotic that is perform to treat many types of contagions initiated by bacteria. So, the existence of compelling ligand must affect the activity of metal in our plasma, blood and tissues. Thus, the study of the probable communication of Ceftibuten with important as well elements existing in the body. Ceftibuten has been interacted with $\mathrm{Zn}$ (metal), $\mathrm{Mg}$ (antacid) as an in-vitro analysis. Also the anti-microbial action of the Ceftibuten with the complexes were dogged. The aforementioned has been detected that Ceftibuten interrelates with metal at $\mathrm{pH}$ 7.4. This research work confirms that there was a possible interaction between the Ceftibuten and metal $\mathrm{Zn}$ and antacid $\mathrm{Mg}$ which was confirms by jobs plot method and by antimicrobial investigation it was confirmed that the zone of inhibition of Ceftibuten with Metal $\mathrm{Zn}$ and antacid $\mathrm{Mg}$ reduced from $16 \mathrm{~mm}$ to $14 \mathrm{~mm} \& 13 \mathrm{~mm}$ respectfully. The stock Ceftibuten disk similarly confirmed in contradiction of Staphylococcus aureus. With the intention of examine the amount of metal ions complicated in complexation through Ceftibuten complexes were revealed by plotting numerous UV spectrophotometric approaches.
\end{abstract}

Keywords: Ceftibuten; Interaction; Complexation; Job's Plot; Antimicrobial activity

\section{Introduction}

Ceftibuten is a vocally vigorous third group cephalosporin. It has also an extensive spectrum of in vitro sterile action, surrounding widely held of the Gram-negative bacteria like streptococci, as well as which spectacles superior steadiness than numerous additional cephalosporins in contradiction of bacteria generating prolonged range beta-lactamases [1]. Ceftibuten is a verbally energetic third group cephalosporin and it has a broad range of in vitro sterile activity, surrounding the widely held of Gram-negative bacteria like streptococci as well a sit displays superior stability than numerous additional cephalosporins against microorganisms creating prolonged range $\beta$-lactamases [2]. Ceftibuten the molecular weight of Ceftibuten is 410.43 [3]. Different types of interactions can happen out of unintentional misuse and also due to shortage of knowledge roughly the energetic ingredients convoluted in the related materials [4]. Two medicines are antagonistic and then their interaction bases a reduction in the belongings of one otherwise both of the medicines [5]. The altered reactions of any receptor to the act of a medicine has caused in a amount of arrangements, which practice standings for example "partial agonist", "competitive agonist" [6]. This one is uniform likely that numerous authors would misemploy any given arrangement [7]. The significant metal current in body is iron and it plays a dominant part in all alive cells. Usually iron campuses are cast-off in the transportation of oxygen in plasma, blood as well as tissues [8]. A mature at rest ingests $250 \mathrm{ml}$ of clean oxygen per minute and oxygen supported by metal compound transportation system recognized heame and alloying oxygen to dispensation the blood as soon as it spreads the tissue [9]. Ceftibuten, a verbally active cephalosporin, has been demonstrated to consume antibacterial action in vitro in contradiction of an inclusive variety of gramnegative as well as definite gram-positive bacteria [10]. The aforementioned activity in contradiction of shared respiratory tract bacteria was originated to be greater or analogous to those stated for additional oral cephalosporins [11].

\section{Materials and Methods}

Ceftibuten solution $250 \mathrm{ml}$ of $1 \times 10^{-2} \mathrm{M}$ was prepared by dissolving $1.386 \mathrm{gm}$ of solution of Ceftibuten in 250 milliliters of demineralized water was passed in 250 milliliters flask. The standard solution was thinned to chosen strong point through buffer solution. [Table 1] 


\section{Preparation of metal solutions}

For the grounding of $0.01 \mathrm{M}$ solution, zinc sulfate hepta hydrate $(0.28754 \mathrm{gm})$ was weighed exactly and bring together with the assistance of funnel was passed in 100 milliliters flask alone, run in demineralized water as well as framework to the spot with the identical solvent. These prime solutions were again thinned ten pleats in the identical solvent as well as the ultimate solutions were $0.0001 \mathrm{M}$ concentration.

\section{Preparation of antacid solution}

For the grounding of $0.01 \mathrm{M}$ antacid solution, magnesium hydroxide $(0.0740 \mathrm{gm})$ was weighed exactly as well as presented with the assistance of funnel in a 100.00 milliliters flask alone, run in demineralized water as well as framework to the spot with the identical solvent. These prime solutions were again diluted ten pleats in the identical solvent as well as the ultimate solutions were $0.0001 \mathrm{M}$ concentration.

\section{Preparation of buffer solution}

To formulate the buffer solution like 1.76 gram of disodium hydrogen phosphate was run in demineralized water through 2.43 gram of solution dihydrogen phosphate as well as $\mathrm{pH}$ was accustomed to $\mathrm{pH} 7.4$ as well as volume was ready to 1000 milliliters through the identical solution.

Table 1: List of chemicals and reagents.

\begin{tabular}{|c|c|c|}
\hline Serial No & Name & Source \\
\hline 1 & Ceftibuten & $\begin{array}{c}\text { Gift samples from Eskayef } \\
\text { Bangladesh Ltd. }\end{array}$ \\
\hline 2 & Zinc Sulphate(Metal) & Merck Itd, Mumbai, India \\
\hline 3 & $\begin{array}{c}\text { Magnesium } \\
\text { Hydroxide(Antacid) }\end{array}$ & Merck Itd, Mumbai, India \\
\hline 4 & $\begin{array}{c}\text { Sodium di-hydrogen } \\
\text { phosphate }\end{array}$ & $\begin{array}{c}\text { USTC, Foys lake, Chittagong, } \\
\text { dept of pharmacy }\end{array}$ \\
\hline 5 & $\begin{array}{c}\text { Disodium hydrogen } \\
\text { phosphate }\end{array}$ & $\begin{array}{c}\text { USTC, Foys lake, Chittagong, } \\
\text { dept of pharmacy }\end{array}$ \\
\hline 6 & Phosphate Buffer & $\begin{array}{c}\text { USTC, Foys lake, Chittagong, } \\
\text { dept of pharmacy }\end{array}$ \\
\hline
\end{tabular}

Table 2: List of instruments \& equipment.

\begin{tabular}{|l|c|c|}
\hline \multicolumn{1}{|c|}{ Name } & Model & Source \\
\hline pH Meter & PH-211 & Hanna, Romania \\
\hline UV spectrophotometer & T80 & PG instrument Ltd, England \\
\hline Electronic Balance & AL-204 & Mettlertoleddo, Switzerland \\
\hline Pipette & & Fischer scientific, Germany \\
\hline
\end{tabular}

Table 3: Standard curve of Ceftibuten.

\begin{tabular}{|c|c|}
\hline $\mathbf{M \times 1 0 ^ { - 5 }}$ & Absorbance \\
\hline 1 & 0.283 \\
\hline 2 & 0.394 \\
\hline 3 & 0.405 \\
\hline 4 & 0.51 \\
\hline 5 & 0.519 \\
\hline 6 & 0.529 \\
\hline 7 & 0.546 \\
\hline 8 & 0.553 \\
\hline 9 & 0.564 \\
\hline
\end{tabular}

\section{Preparation of typical curve of Ceftibuten}

Ceftibuten standard solution at a $\mathrm{pH} 7.4$ as well as concentration of $1 \times 10^{-5} \mathrm{M}$ was supplemented in altered concentrations to ten tubes and to have succeeding concentrations: $9 \times 10^{-5} \mathrm{M}, 8 \times 10^{-5} \mathrm{M}, 7 \times 10^{-5} \mathrm{M}$, $6 \times 10^{-5} \mathrm{M}, 5 \times 10^{-5} \mathrm{M}, 4 \times 10^{-5} \mathrm{M}, 3 \times 10^{-5} \mathrm{M}, 2 \times 10^{-5} \mathrm{M}, 1 \times 10^{-5} \mathrm{M}$. Then these solutions were accurately mixed. Now absorbance of these solutions was dogged at $254 \mathrm{~nm}$ by ultra violet spectrometer. The typical curve was found through plotting absorbance in contradiction of the equivalent concentrations.

\section{Method of Disc Diffusion}

Solution of recognized concentration (Like $3 \mu \mathrm{g} /$ milliliters) of test models are prepared through running measured quantity of the models in premeditated volume of the solvents. Dried as well as sanitized filter paper floppies (like $6 \mathrm{~mm}$ as diameter) are saturated with recognized quantities of test materials using micropipette [9]. Discs holding the test materials are employed on the nutrient agar condition homogeneously seeded through test microorganism, typical antibiotic flop pies as well

Table 4: Absorbance of Ceftibuten at different wavelength.

\begin{tabular}{|c|c|}
\hline Wavelength & Absorbance \\
\hline 200 & 0.038 \\
\hline 210 & 0.041 \\
\hline 220 & 0.125 \\
\hline 230 & 0.197 \\
\hline 240 & 0.014 \\
\hline 250 & 0.029 \\
\hline 260 & 0.008 \\
\hline 270 & 0.048 \\
\hline 280 & 0.030 \\
\hline 290 & -0.009 \\
\hline
\end{tabular}

Table 5: Spectral analysis of Ceftibuten with $\mathrm{Mg}(\mathrm{OH})_{2}$.

\begin{tabular}{|c|c|c|}
\hline Wavelength/nm & $\begin{array}{c}\text { Absorbance of } \\
\text { Ceftibuten }\end{array}$ & $\begin{array}{c}\text { Absorbance of Ceftibuten } \\
\text { with } \mathbf{M g}(\mathbf{O H})_{2}\end{array}$ \\
\hline 200 & 0.038 & 0.539 \\
\hline 210 & 0.041 & 0.703 \\
\hline 220 & 0.125 & 0.654 \\
\hline 230 & 0.197 & 0.31 \\
\hline 240 & 0.014 & 0.179 \\
\hline 250 & 0.029 & 0.095 \\
\hline
\end{tabular}

Table 6: Combined Spectral analysis of Ceftibuten with $\mathrm{ZnSO}_{4} \cdot 7 \mathrm{H}_{2} \mathrm{O}$ and $\mathrm{Mg}(\mathrm{OH})_{2}$.

\begin{tabular}{|l|c|c|c|}
\hline Wavelength/nm & $\begin{array}{c}\text { Absorbance of } \\
\text { Ceftibuten }\end{array}$ & $\begin{array}{c}\text { Absorbance } \\
\text { of Ceftibuten } \\
\text { with } \text { ZnSO }_{4} \cdot \mathbf{H}_{2} \mathbf{O}\end{array}$ & $\begin{array}{c}\text { Absorbance of } \\
\text { Ceftibuten with } \\
\mathbf{M g ( O H})_{2}\end{array}$ \\
\hline 200 & 0.038 & 0.005 & 0.539 \\
\hline 210 & 0.041 & 0.008 & 0.703 \\
\hline 220 & 0.125 & 0.065 & 0.654 \\
\hline 230 & 0.197 & 0.171 & 0.31 \\
\hline 240 & 0.014 & 0.08 & 0.179 \\
\hline 250 & 0.029 & 0.027 & 0.095 \\
\hline
\end{tabular}


as blank floppies are cast-off as positive as well as negative control. These dishes are reserved at very low temperature (like $4^{\circ} \mathrm{C}$ ) for the 24 hour period to permit maximum diffusion. Throughout this time parched discs captivate water from neighbouring media as well as test materials run as well as rambling out of sample substances containing disc. The diffusion happens bestowing to physical law which controls transmission of molecules over agar gel. Resulting there is also a steady modification of test ingredients concentrations in media neighbouring the disc [12]. [Table 2]

\section{Results and Discussions}

From the following table 3 , it can notice that absorbance of Ceftibuten rises with the growing concentration according to Beer Lambert's Law.

From the table 4 we obtained Absorbance of Ceftibuten at different wavelength.

From the table 5, it can observe that the absorbance of Ceftibuten is different when it interacts with $\mathrm{Mg}(\mathrm{OH})_{2}$.

From the table 6, it can observe that relations between Ceftibuten with metal could lead to procedure complexes and which have altered light absorption capacity as well as spectrum is changed. So any alteration and spectrum behavior is regarded as a tool for primary interaction from the spectral studies.
From the above we can observe that Ceftibuten forms resilient 1:1 complexes through zinc sulfate hepta hydrate which is indicated as inverted ' $V$ ' shaped curve. [Table 7]

From the above we can observe that Ceftibuten forms strong 1:1 complexes with $\mathrm{Mg}(\mathrm{OH})$, which is indicated as inverted ' $v$ ' shaped curve. [Table 8]

From the table 9 we obtained combined absorbance of drug with different metal \& antacid

\section{Antimicrobial study}

The antimicrobial strength of the trial agents is dignified by their action to stop the progress of microorganisms adjoining the floppies which provides clear region of inhibition. Later incubation, the antimicrobial actions of test ingredients were dogged by determining the length of the regions of inhibition in $\mathrm{mm}$ through a translucent millimeter scale. The test samples were verified against Staphyloccopcus aureus. The typical ceftriaxone disk also verified against Staphyloccopcus aureus. The outcomes of antimicrobial action, dignified in terms of the diameter of region of inhibition in millimeter are presented in table 10 .

Antimicrobial sensitivity testing of Ceftibuten against Staphylococcus aureus after interacting with $\mathrm{ZnSO}_{4} \cdot 7 \mathrm{H}_{2} \mathrm{O}$ and $\mathrm{Mg}(\mathrm{OH})_{2}$ solution respectively.

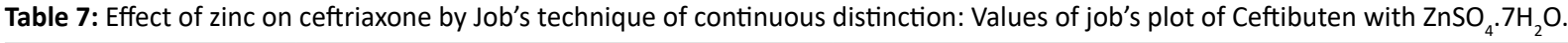

\begin{tabular}{|c|c|c|c|c|c|}
\hline $\begin{array}{l}\text { Concentration of } \\
\text { Ceftibuten }\left(\mathrm{M} \times 10^{-5}\right)\end{array}$ & $\begin{array}{l}\text { Absorbance of } \\
\text { Ceftibuten (A) }\end{array}$ & 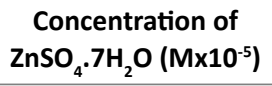 & $\begin{array}{l}\text { Absorbance of } \\
\mathrm{ZnSO}_{4} \cdot 7 \mathrm{H}_{2} \mathrm{O}(\mathrm{B})\end{array}$ & Absorbance of mixture (C) & $\begin{array}{l}\text { Absorbance difference } \\
\qquad(D=(A+B)-C)\end{array}$ \\
\hline 1 & 0.283 & 9 & 0.176 & 0.082 & 0.377 \\
\hline 2 & 0.394 & 8 & 0.182 & 0.095 & 0.481 \\
\hline 3 & 0.405 & 7 & 0.185 & 0.104 & 0.489 \\
\hline 4 & 0.51 & 6 & 0.19 & 0.104 & 0.596 \\
\hline 5 & 0.519 & 5 & 0.193 & 0.108 & 0.604 \\
\hline 6 & 0.529 & 4 & 0.183 & 0.135 & 0.577 \\
\hline 7 & 0.546 & 3 & 0.17 & 0.142 & 0.574 \\
\hline 8 & 0.553 & 2 & 0.168 & 0.149 & 0.572 \\
\hline 9 & 0.564 & 1 & 0.164 & 0.153 & 0.575 \\
\hline
\end{tabular}

Table 8: Values of Job plot of Ceftibuten and $\mathrm{Mg}(\mathrm{OH})_{2}$.

\begin{tabular}{|c|c|c|c|c|c|}
\hline $\begin{array}{l}\text { Concentration of } \\
\text { Ceftibuten }\left(\mathrm{M} \times 10^{-5}\right)\end{array}$ & $\begin{array}{l}\text { Absorbance of Ceftibuten } \\
\text { (A) }\end{array}$ & $\begin{array}{c}\text { Concentration of } \\
\mathrm{ZnSO}_{4} \cdot 7 \mathrm{H}_{2} \mathrm{O}\left(\mathrm{Mx}^{-5} 0^{-5}\right)\end{array}$ & $\begin{array}{l}\text { Absorbance of } \\
\mathrm{ZnSO}_{4} .7 \mathrm{H}_{2} \mathrm{O}(\mathrm{B})\end{array}$ & $\begin{array}{l}\text { Absorbance of } \\
\text { mixture (C) }\end{array}$ & $\begin{array}{l}\text { Absorbance difference } \\
\qquad(D=(A+B)-C)\end{array}$ \\
\hline 1 & 0.283 & 9 & 0.076 & 0.107 & 0.252 \\
\hline 2 & 0.394 & 8 & 0.079 & 0.114 & 0.459 \\
\hline 3 & 0.405 & 7 & 0.083 & 0.12 & 0.368 \\
\hline 4 & 0.51 & 6 & 0.089 & 0.127 & 0.472 \\
\hline 5 & 0.519 & 5 & 0.096 & 0.132 & 0.483 \\
\hline 6 & 0.529 & 4 & 0.095 & 0.143 & 0.481 \\
\hline 7 & 0.546 & 3 & 0.081 & 0.148 & 0.479 \\
\hline 8 & 0.553 & 2 & 0.076 & 0.152 & 0.477 \\
\hline 9 & 0.564 & 1 & 0.073 & 0.162 & 0.475 \\
\hline
\end{tabular}


Table 9: Combined absorbance of drug with different metal \& antacid.

\begin{tabular}{|c|c|c|}
\hline Ceftibuten & Ceftibuten with $\mathrm{ZnSO}_{\mathbf{4}} . \mathbf{7 H}_{\mathbf{2}} \mathbf{O}$ & Ceftibuten with $\mathbf{M g}(\mathbf{O H})_{\mathbf{2}}$ \\
\hline 0.283 & 0.176 & 0.076 \\
\hline 0.394 & 0.182 & 0.079 \\
\hline 0.405 & 0.185 & 0.083 \\
\hline 0.51 & 0.19 & 0.089 \\
\hline 0.519 & 0.193 & 0.096 \\
\hline 0.529 & 0.183 & 0.095 \\
\hline 0.546 & 0.17 & 0.081 \\
\hline 0.553 & 0.168 & 0.076 \\
\hline 0.564 & 0.164 & 0.073 \\
\hline
\end{tabular}

Table 10: Diameter of zone of inhibition.

\begin{tabular}{|l|c|l|}
\hline \multicolumn{1}{|c|}{$\begin{array}{c}\text { Name of } \\
\text { Bacteria }\end{array}$} & $\begin{array}{c}\text { Typical disk (zone } \\
\text { of inhibition/mm) }\end{array}$ & Sample disk (zone of inhibition) \\
\hline $\begin{array}{l}\text { Staphylococcus } \\
\text { aureus }\end{array}$ & $16 \mathrm{~mm}$ & Ceftibuten $+\mathrm{ZnSO}_{4} \cdot 7 \mathrm{H}_{2} \mathrm{O}_{14 \mathrm{~mm}}$ \\
\hline $\begin{array}{l}\text { Staphylococcus } \\
\text { aureus }\end{array}$ & $16 \mathrm{~mm}$ & Ceftibuten with $\mathrm{Mg}(\mathrm{OH})_{2} 13 \mathrm{~mm}$ \\
\hline
\end{tabular}

\section{Conclusion}

The advanced spectrophotometric method is easy, direct as well as lucrative for the determination of drug. From this research study, this has been understood that Ceftibuten provides a strident peak at $254 \mathrm{~nm}$. At what time Zinc Sulfate as well as antacid solution, $\mathrm{Mg}(\mathrm{OH})_{2}$ mixed with Ceftibuten 1:1 ratio, the strength of peak deviations extraordinarily. The antimicrobial transmission of a mediator is vital to determine its spectrum in contradiction of various kinds of the pathogenic organisms. The exposure of entity to antimicrobial mediators can be dignified in vitro through number of methods surrounded by which disk diffusion technique using altered concentration of mediators absorbed on substantial filter paper of the disks, is extensively satisfactory for the introductory assessment of antimicrobial action. Job's plot has specified molar ratio of the complexes of Ceftibuten with Zinc Sulfate as well as antacid solution, $\mathrm{Mg}(\mathrm{OH})_{2}$. At the $\mathrm{pH}$ 7.4 Ceftibuten formula eresilient 1:1 complexes through Zinc Sulfate as well as antacid solution, $\mathrm{Mg}(\mathrm{OH})_{2}$ designated by way of ' $\wedge$ ' shaped curves. Such curves may design at resilient kinetics of the complexation among Ceftibuten with Zinc Sulfate and antacid solution, magnesium hydroxide. The trial samples were verified in contradiction of Staphylococcus aureus. The typical Ceftibuten disk also verified against Staphylococcus aureus. It was detected that the antimicrobial action of Ceftibuten reductions when this forms complexes through $\mathrm{ZnSO}_{4} \cdot 7 \mathrm{H}_{2} \mathrm{O}$ as well as antacid solution, magnesium hydroxide. So, by antimicrobial examination it was established that the zone of inhibition of Ceftibuten with Metals $\mathrm{Zn}$, $\mathrm{Mg}$ reduced from $16 \mathrm{~mm}$ to $14 \mathrm{~mm} \& 13 \mathrm{~mm}$ respectfully.

\section{References}

1. Anon (1987) Criteria for the evaluation of the clinical efficacy of antimicrobial agents on urinary tract infections ( $3^{\text {rd }}$ edition). Japanese Journal of Antibiotics 40: 2149-2191.

2. Jones RN, Barry AL (1988) Ceftibuten, (7432-S), SCH 39720: comparative antimicrobial activity against 4735 clinical isolates, beta-lactamase stability and broth dilution quality control guidelines. Eur J Clin Microbiol Infect Dis 7: 802-807.

3. Barr WH, Lin CC, Radwanski E, Lim J, Symchowicz S, et al. (1991) The pharmacokinetics of ceftibuten in humans. Diagn Microbiol Infect Dis 14: 93-100.

4. Shah MN, Patel HU, Patel CN (2012) Development and validation of spectrophotometric method for simultaneous determination of cefpodoxime proxetil and ofloxacin in tablets. Int J Pharm Sci Res 38: 551-555.

5. Jagatap CA, Patil PB, Kane SR, Mohite SK, Magdum CS (2012) Development and validation of simultaneous spectro-photometric estimation of cefpodoxime proxetil and ofloxacin in tablet dosage form. J Pharm Res 5: 3181.

6. S Koppisett V, Chandra N (2011) Influence of Alcohol and Smoking on Drug Action: A Step for better utilization of drugs. J Chem Pharm Res 30: 242-248.

7. Chou TC (2006) Theoretical basis, experimental design, and computerized simulation of synergism and antagonism in drug combination studies. Pharmcol rev 58: 621-681.

8. Sadowski DC (2012) Drug interactions with antacids. Mechanisms and clinical significance. Drug Saf 11: 395-407.

9. Tallarida RJ (2001) Drug synergism: its detection and applications. J Pharmacol Exp Ther 298: 865-872.

10. Aronson JK (2004) Drug interactions-information, education, and the British National Formulary. Br J Clin Pharmacol 57: 371-372.

11. Wise R, Nye K, O'Neill P, Westenholme M, Andrew JM (1990) Pharmacokinetics and tissue penetration of ceftibuten. Antimicrob Agents Chemother. 34: 1053-1055.

12. Patil V, Chaudari RY (2012) Spectrophotometric method for estimation of cefpodoxime proxetil and ofloxacin in tablet dosage form by simultaneous equation method. Int J Pharm Life Sci 3: 19821984. 